\title{
TYPHOON-FORCED WAVES AROUND A WESTERN PACIFIC ISLAND NATION
}

By Sophia T. Merrifield, Travis A. Schramek, Sean Celona, Ana Beatriz Villas Bôas, Patrick L. Colin, and Eric J. Terrill

\section{August 15, 2010}

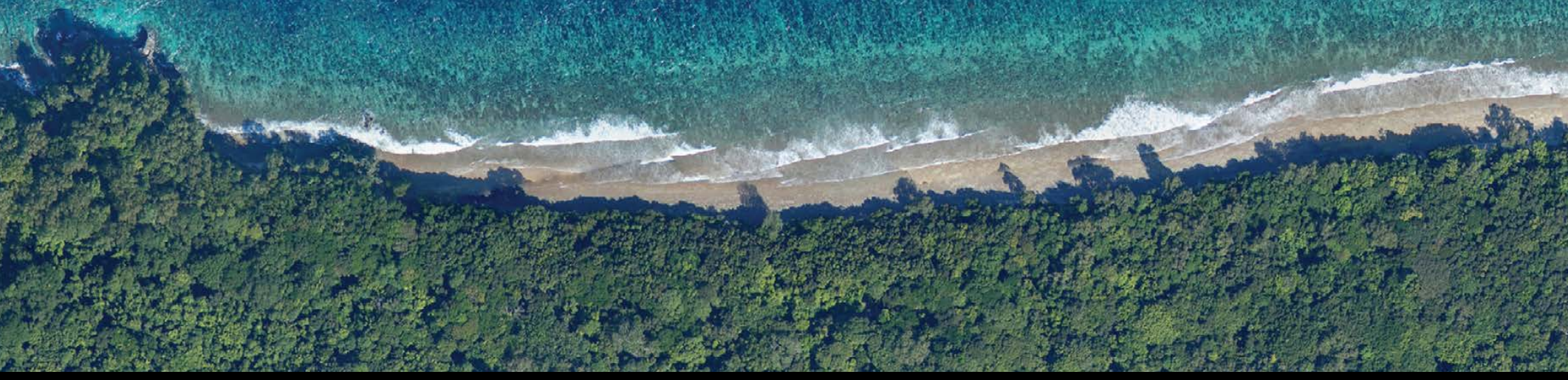

August 9,2013

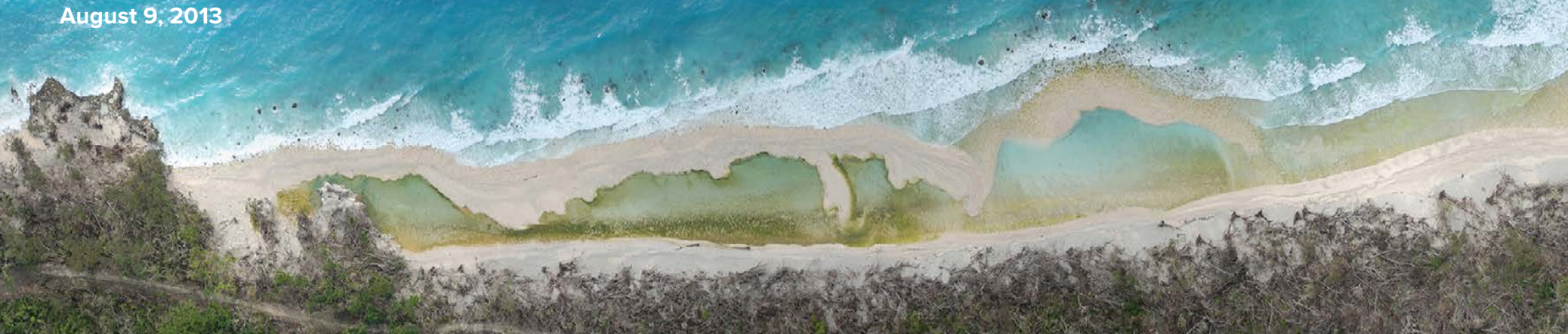

May 28, 2017

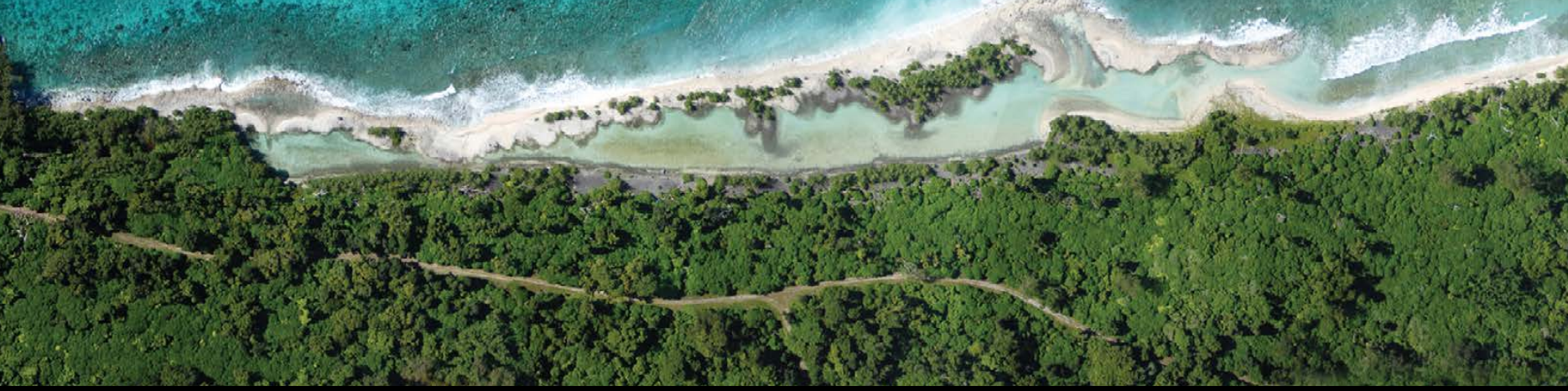

Vertical aerial images of the east coast of Angaur Island, Palau. (top) Coastline conditions prior to Typhoon Bopha, the first of three storms discussed in this paper. (middle) Destruction of vegetation and the creation of a large rubble berm caused by wave overtopping during Typhoon Bopha. (bottom) Stabilization of berms by growth of trees and other vegetation four years after Typhoon Bopha. Photo credit: Patrick L. Colin, CRRF 


\section{Images of typhoon-driven destruction to the island nation of Palau illustrate the range of impacts to Palau's diverse coastline and the need for persistent measurements to capture the complexity associated with extreme events.}

ABSTRACT. Over the last decade, the Pacific island nation of Palau, situated at $7^{\circ} \mathrm{N}$, has had a number of close encounters with Category 4 and 5 typhoons, including the named storms Bopha, Haiyan, and Lan in 2012, 2013, and 2017, respectively. Although historically, due to its low latitude location, typhoon activity has been rare in Palau, it was in the direct path of typhoons Bopha and Haiyan, which caused extensive wind damage, reef destruction, and wave-driven inundation across the island group. Typhoon Lan formed and stalled northwest of the main island group, generating large swell that damaged the coral communities on the western barrier reefs of Palau. Wave gauges deployed in water depths of 9-17 $\mathrm{m}$ around the island group captured strong gradients in the surface wave field during each typhoon. Significant wave height measured by the pressure gauges varied by as much as $5 \mathrm{~m}$, highlighting the importance of coastline and reef geometry in wave transformation and shadowing. WAVEWATCH III model hindcasts are used to interpret the observed gradients in the data sets, characterize the offshore incident wave direction during the storms, and describe shadowing of swell by the island chain. Coral damage that occurred during the storms is linked to the relative orientation of the coastline and the dominant swell wave direction. This study establishes a framework for identifying vulnerable coastline areas that may benefit Palau's preparedness efforts and informs resolution requirements for applying regional wave models to support risk assessments at islands with complex shorelines and steep bathymetry.

IN PLAIN WORDS. This study describes surface wave conditions around the western Pacific island nation of Palau during three major typhoons that caused coral reef destruction, wave-driven inundation, and wind-driven infrastructure damage. A combination of nearshore observations from wave gauges and offshore wave model output is used to relate areas of maximum coastline damage to the incident wave conditions.

\section{INTRODUCTION}

With an average of over 25 typhoons per year (https://www.metoc.navy.mil/jtwc/ jtwc.html?western-pacific), the western Pacific Ocean is the most active storm generation region on Earth. Typhoons, as tropical cyclones are named in the northwestern Pacific, form over warm ocean waters and propagate westward, often dissipating over land or via extratropical transition. Historically, typhoon-driven winds and waves have caused extensive damage to vessels, island nations, and marine environments in the western Pacific. During World War II, Typhoon Cobra struck the US Pacific Fleet in the Philippine Sea, capsizing three destroyers and causing close to 1,000 casualties. More recently, Super Typhoons Mangkhut and Haiyan have caused an estimated US \$3-5 billion in damage.

The wave climate during typhoons is composed of long-period swell ( 10-20 s period) that can outpace the generating storm's propagation and locally driven waves ( $~ 5-10 \mathrm{~s}$ period) that are forced by strong winds associated with the storm. The cyclonic nature of typhoon winds, coupled with the propagating storm center, results in the largest waves occurring in the forward quadrant right of the eye center as a result of extended fetch conditions (Holthuijsen et al., 2012; Black et al., 2017). Long-period swells encountering islands are shadowed, a process characterized by wave refraction and diffraction that can be predicted with traditional ray tracing techniques. As waves approach the shoreline, fringing and barrier reefs provide protection to shoreline communities (e.g., Monismith, 2007). While higher frequency waves are attenuated as they sweep over reefs, energy transfer to lower frequencies can lead to resonant amplification of infragravity waves ( 25-300 s period; Péquignet et al., 2009; Becker et al., 2016; Gawehn et al., 2016). Infragravity energy, which can dominate runup, contributed to significant shoreline damage in the Philippines during Typhoon Haiyan (Roeber and Bricker, 2015; Shimozono et al., 2015).

The Republic of Palau is situated at the eastern edge of the Pacific Warm Pool in the Intertropical Convergence Zone and is subject to heavy rainfall, particularly between June and August, due to the West Pacific Monsoon. Seasonal winds near Palau are predominately from the southwest between June and October, 
with strong, episodic events from the northeast between November and May driven by the trade winds (Kubota et al., 2005). Historically, infrequent but occasionally intense typhoon activity has occurred at Palau's low latitude location $\left(7^{\circ} \mathrm{N}\right)$; the last major storm prior to this study was Super Typhoon Mike in 1990 (Chu et al., 2012; CRRF, 2014). The main island group is surrounded by over $500 \mathrm{~km}$ of reef ecosystems that include barrier and fringing reefs and protected lagoons. Coral reef damage has been documented as a result of seasonal and interannual temperature changes and after the recent increase in typhoon activity (Colin and Linfield, 2019).

Measurements used in this study were collected as part of the Office of Naval Research-funded Flow Encountering Abrupt Topography (FLEAT) Departmental Research Initiative. Meteorological and nearshore sensors have been deployed and maintained since 2012, providing situational awareness of environmental conditions seasonally and interannually. Measurements were collected during a number of severe wind and wave conditions associated with tropical storms as well as the 2014-2016 El Niño that resulted in large sea level variability at Palau (Schramek et al., 2018) and intense drought within the region (King et al., 2016). In this study, we investigate the nearshore wave climate during three major typhoons using an array of wave gauge measurements and the WAVEWATCH III surface wave model. The sea, swell, and infragravity significant wave heights $(H s)$ at the nearshore gauges are estimated and related to the offshore wave climate. Evidence of coral reef damage along particular areas of the shoreline is tied to the relative angle between incident waves and the shoreline orientation. Conclusions and further work are discussed in the final section.

\section{STORMS}

The three typhoons discussed in this study were Category 4 or 5 storms that passed close to or over part of Palau. Bopha and Haiyan similarly tracked from east to west with maximum damage to the "right" of the storm track, hitting Palau's southern and northern regions, respectively. Lan was unique in that storm genesis and intensification occurred near and around the island group, and then the storm stalled, radiating wave energy toward Palau's western barrier reef. A brief description of each storm is given below.

\section{Typhoon Bopha}

Typhoon Bopha began as a tropical depression close to the equator. The typhoon center passed $40 \mathrm{~km}$ south of Angaur Island, slightly south of the main Palau island group, on December 2, 2012, at approximately 13:00 UTC before heading west-northwest to the Philippines, where it caused extensive damage (Figure 1a). At Palau, storm damage was documented on eastward-facing reefs from Angaur to Babeldaob; sediment plumes mobilized by the storm extended over $150 \mathrm{~km}$ to sea and were visible from space.

\section{Typhoon Haiyan}

Typhoon Haiyan began as a region of low pressure east-southeast of Pohnpei before heading westward and pass-

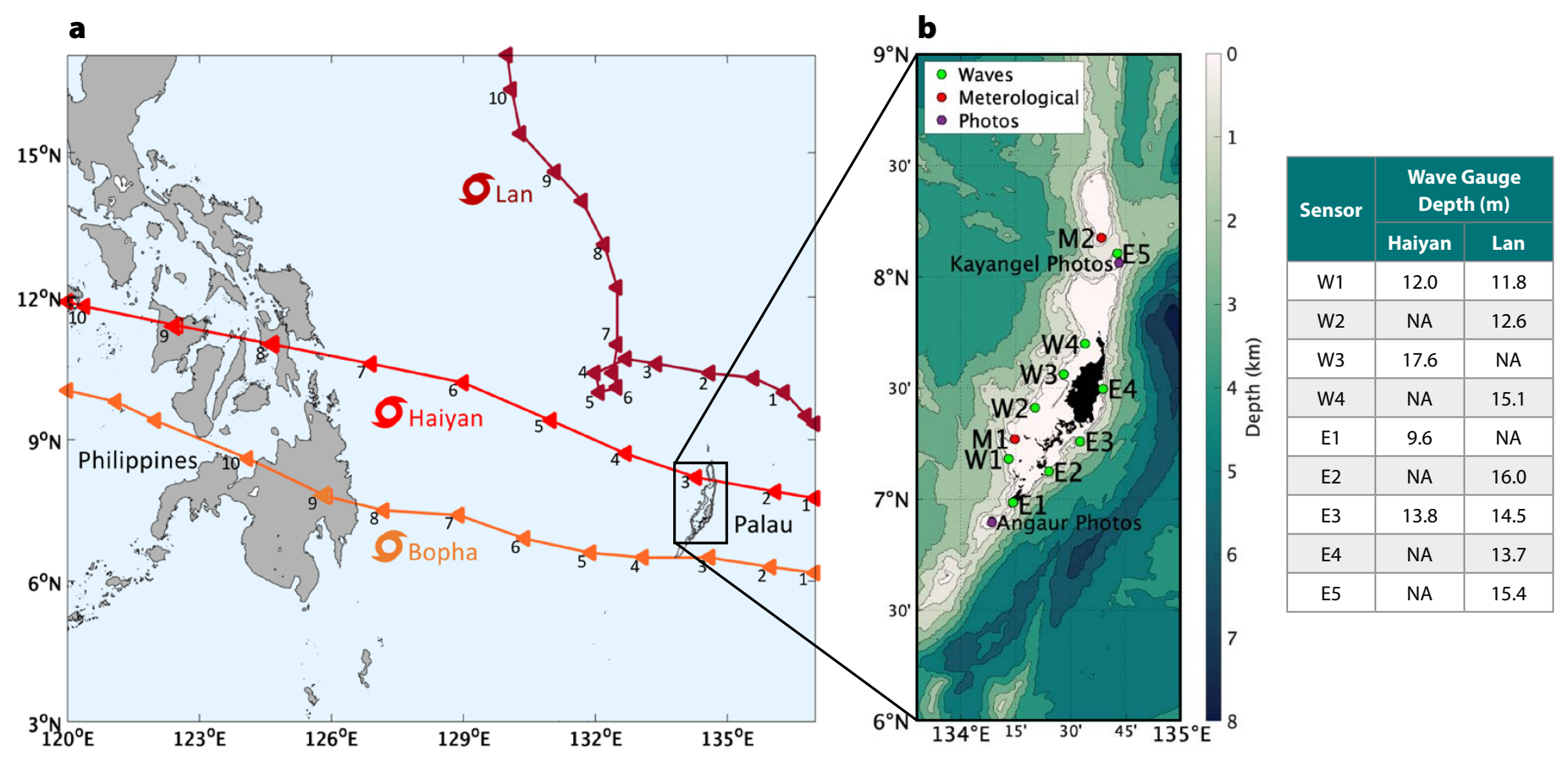

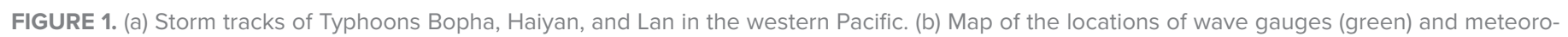

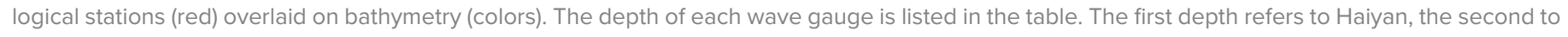

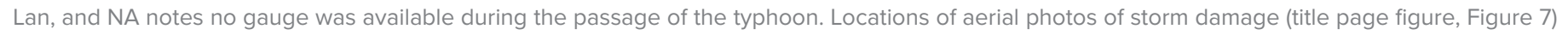
are shown in purple. 
ing north of the main Palau island group, on November 6, 2013, at approximately 16:00 UTC. The typhoon had a similar path to that of Bopha but offset to the north by $180 \mathrm{~km}$ (Figure 1a), so that it passed directly over Kayangel Atoll, Palau's northernmost state, where it caused extensive damage from winds, reef destruction from waves, and inundation on its eastern island shore.

\section{Typhoon Lan}

Typhoon Lan began as a tropical disturbance near Chuuk and had the northernmost origin of the three storms. The typhoon passed north of Palau, then stalled, and rapidly intensified about $400 \mathrm{~km}$ northwest of Palau before turning northward and heading toward Japan, where the most significant damage was reported. At its closest point, Lan came within $250 \mathrm{~km}$ of northern Palau, but reports of damage were minimal as this was prior to intensification and the storm never made landfall. The majority of the damage in Palau was due to large swells that radiated to the offshore western barrier reefs, which protect the lagoon and land area of the main island group. The island State of Angaur, located just south of the main island group, has no protective barrier reefs and sustained the worst damage to shore environments from swells directly impacting the western coastline. Because the main island group is surrounded by offshore barrier reefs, the general populace was unaware of the large waves battering the reefs as the storm tracked northward. Lan resulted in severe damage to coral reef communities on west-facing reefs.

\section{NEARSHORE OBSERVATIONAL DATA}

Wind measurements were made using two Scripps-fabricated Expeditionary Weather Stations (XMETs). The XMET incorporates a Vaisala WXT530 weather sensor to report atmospheric pressure, temperature, humidity, rainfall, wind direction, speed, and gust using World Meteorological Organization (WMO) standards. The sensors, which were mounted $2.9 \mathrm{~m}$ off the ground, have a wind speed observation range of $0-60 \mathrm{~m} \mathrm{~s}^{-1}$, a wind speed accuracy of $3 \%$ at $10 \mathrm{~m} \mathrm{~s}^{-1}$, and a wind direction accuracy of $\pm 3^{\circ}$ at $10 \mathrm{~m} \mathrm{~s}^{-1}$. M1 was deployed on Ongingiang Island, a tiny low island on the western barrier reef of Palau, more than $15 \mathrm{~km}$ from any substantive land mass. M2 was deployed on Ngeruangel, another small, uninhabited island $14 \mathrm{~km}$ northwest of Kayangel. Meteorological measurements were collected once per hour, averaged over a 10-minute burst at $1 \mathrm{~Hz}$ sampling rate. Wind speeds and barometric pressures measured during typhoons Bopha, Haiyan, and Lan are listed in Table 1.

A network of RBR Duo wave gauges was deployed around the islands of Palau in water depths ranging from $9 \mathrm{~m}$ to $17 \mathrm{~m}$ (Figure 1b). A subset of the stations was in place during typhoons Haiyan (W1, $\mathrm{W} 3, \mathrm{E} 1, \mathrm{E} 3)$ and Lan (W1, W2, W4, E2, E3, E4, E5). Distribution of instruments was generalized for east and west sides of Palau ( $\mathrm{E}=$ east, $\mathrm{W}=$ west $)$ with the exception of E5, which was located at the northern tip of Kayangel Atoll and exposed to swell from both east and west directions. (E5 was lost during Haiyan when the storm wiped the reef clean.) The sensors measured bottom pressure in 17-minute bursts at a sampling frequency of $1 \mathrm{~Hz}$. All sensors sampled once per hour with the exception of stations W1 and W4 during typhoon Lan, which sampled every 30 minutes. The elevation spectrum or wave energy spectrum, $E_{f}$, is related to the pressure spectrum, $S_{p p}$, as follows (e.g., Bishop and Donelan, 1987):

$$
\mathrm{E}_{\mathrm{f}}(\omega)=S_{p p}(\omega) / K_{p}^{2}
$$

$K_{p}$ is the pressure response function defined as

$$
K_{p}(\omega)=\frac{\cosh (k(h+z))}{\cosh (k h)},
$$

TABLE 1. Records of wind speed and barometric pressure along the storm tracks shown in Figure 1a for typhoons Bopha, Haiyan, and Lan. The values listed in bold text represent the time that each typhoon was in closest proximity to Palau. Data are available at https://www.metoc.navy.mil/jtwc/jtwc.

\begin{tabular}{|c|c|c|c|c|c|c|c|c|c|c|}
\hline \multirow{2}{*}{$\begin{array}{c}\text { STORM } \\
\text { (Year) }\end{array}$} & \multicolumn{10}{|c|}{ STORM TRACK LOCATIONS } \\
\hline & 1 & 2 & 3 & 4 & 5 & 6 & 7 & 8 & 9 & 10 \\
\hline \multirow{4}{*}{$\begin{array}{l}\text { Bopha } \\
(2012)\end{array}$} & Dec 2 & Dec 2 & Dec 2 & Dec 2 & $\operatorname{Dec} 3$ & $\operatorname{Dec} 3$ & Dec 3 & Dec 3 & Dec 4 & $\operatorname{Dec} 4$ \\
\hline & 00:00 & 06:00 & $12: 00$ & $18: 00$ & 00:00 & 00:00 & $12: 00$ & $18: 00$ & 00:00 & 06:00 \\
\hline & $67 \mathrm{~m} \mathrm{~s}^{-1}$ & $69 \mathrm{~m} \mathrm{~s}^{-1}$ & $69 \mathrm{~m} \mathrm{~s}^{-1}$ & $59 \mathrm{~m} \mathrm{~s}^{-1}$ & $54 \mathrm{~m} \mathrm{~s}^{-1}$ & $54 \mathrm{~m} \mathrm{~s}^{-1}$ & $72 \mathrm{~m} \mathrm{~s}^{-1}$ & $72 \mathrm{~m} \mathrm{~s}^{-1}$ & $57 \mathrm{~m} \mathrm{~s}^{-1}$ & $49 \mathrm{~m} \mathrm{~s}^{-1}$ \\
\hline & $926 \mathrm{hPa}$ & $922 \mathrm{hPa}$ & $922 \mathrm{hPa}$ & $937 \mathrm{hPa}$ & $944 \mathrm{hPa}$ & $944 \mathrm{hPa}$ & $918 \mathrm{hPa}$ & 918 hPa & $941 \mathrm{hPa}$ & $952 \mathrm{hPa}$ \\
\hline \multirow{4}{*}{$\begin{array}{l}\text { Haiyan } \\
(2013)\end{array}$} & Nov 6 & Nov 6 & Nov 6 & Nov 7 & Nov 7 & Nov 7 & Nov 7 & Nov 8 & Nov 8 & Nov 8 \\
\hline & 06:00 & $12: 00$ & 18:00 & 00:00 & 06:00 & $12: 00$ & $18: 00$ & 00:00 & 06:00 & $12: 00$ \\
\hline & $69 \mathrm{~m} \mathrm{~s}^{-1}$ & $77 \mathrm{~m} \mathrm{~s}^{-1}$ & $80 \mathrm{~m} \mathrm{~s}^{-1}$ & $80 \mathrm{~m} \mathrm{~s}^{-1}$ & $82 \mathrm{~m} \mathrm{~s}^{-1}$ & $87 \mathrm{~m} \mathrm{~s}^{-1}$ & $87 \mathrm{~m} \mathrm{~s}^{-1}$ & $85 \mathrm{~m} \mathrm{~s}^{-1}$ & $75 \mathrm{~m} \mathrm{~s}^{-1}$ & $67 \mathrm{~m} \mathrm{~s}^{-1}$ \\
\hline & $922 \mathrm{hPa}$ & $911 \mathrm{hPa}$ & $907 \mathrm{hPa}$ & $907 \mathrm{hPa}$ & $903 \mathrm{hPa}$ & $895 \mathrm{hPa}$ & $895 \mathrm{hPa}$ & 899 hPa & $914 \mathrm{hPa}$ & $926 \mathrm{hPa}$ \\
\hline \multirow{4}{*}{$\begin{array}{c}\text { Lan } \\
(2017)\end{array}$} & Oct 15 & Oct 16 & Oct 16 & Oct 17 & Oct 17 & Oct 17 & Oct 17 & Oct 18 & Oct 18 & Oct 19 \\
\hline & $18: 00$ & $06: 00$ & $12: 00$ & 00:00 & 03:00 & 06:00 & $18: 00$ & 06:00 & $18: 00$ & 06:00 \\
\hline & $15 \mathrm{~m} \mathrm{~s}^{-1}$ & $18 \mathrm{~m} \mathrm{~s}^{-1}$ & $21 \mathrm{~m} \mathrm{~s}^{-1}$ & $23 \mathrm{~m} \mathrm{~s}^{-1}$ & $23 \mathrm{~m} \mathrm{~s}^{-1}$ & $26 \mathrm{~m} \mathrm{~s}^{-1}$ & $31 \mathrm{~m} \mathrm{~s}^{-1}$ & $33 \mathrm{~m} \mathrm{~s}^{-1}$ & $36 \mathrm{~m} \mathrm{~s}^{-1}$ & $46 \mathrm{~m} \mathrm{~s}^{-1}$ \\
\hline & 1002 hPa & $1001 \mathrm{hPa}$ & 993 hPa & 989 hPa & 989 hPa & 992 hPa & 979 hPa & 978 hPa & $970 \mathrm{hPa}$ & $956 \mathrm{hPa}$ \\
\hline
\end{tabular}
html?western-pacific. 
where $h$ is the bottom depth, $z$ is the sensor depth, and $k$ is the wavenumber. The expression for $K_{p}$ simplifies when the pressure sensors are bottom mounted (e.g., $\mathrm{z}=-\mathrm{h}$ ) such that

$$
K_{p}(\omega)=\frac{1}{\cosh (k h)} .
$$

The wavenumber is related to the frequency, $\omega$, through the dispersion of surface gravity waves:

$$
\omega=\sqrt{(g k \tanh (k h))} .
$$

The wave energy spectrum is computed with a high-frequency cutoff of $0.25 \mathrm{~Hz}$. The significant wave height, $H s$, is defined as the average of the highest onethird of the waves, and can be obtained from the energy spectrum (LonguetHiggins, 1952; Holthuijsen, 2010) based upon assumptions of the statistics of the wave heights:

$$
H s=4\left(\int_{0}^{\infty} E_{f} d f\right)^{1 / 2} .
$$

\section{WAVEWATCH III MODEL RUNS}

We complement our analysis of the wave field around Palau during the three major typhoons using model output from the WAVEWATCH III (WW3) model version 5.16 (WAVEWATCH III Development Group, 2016). The wave
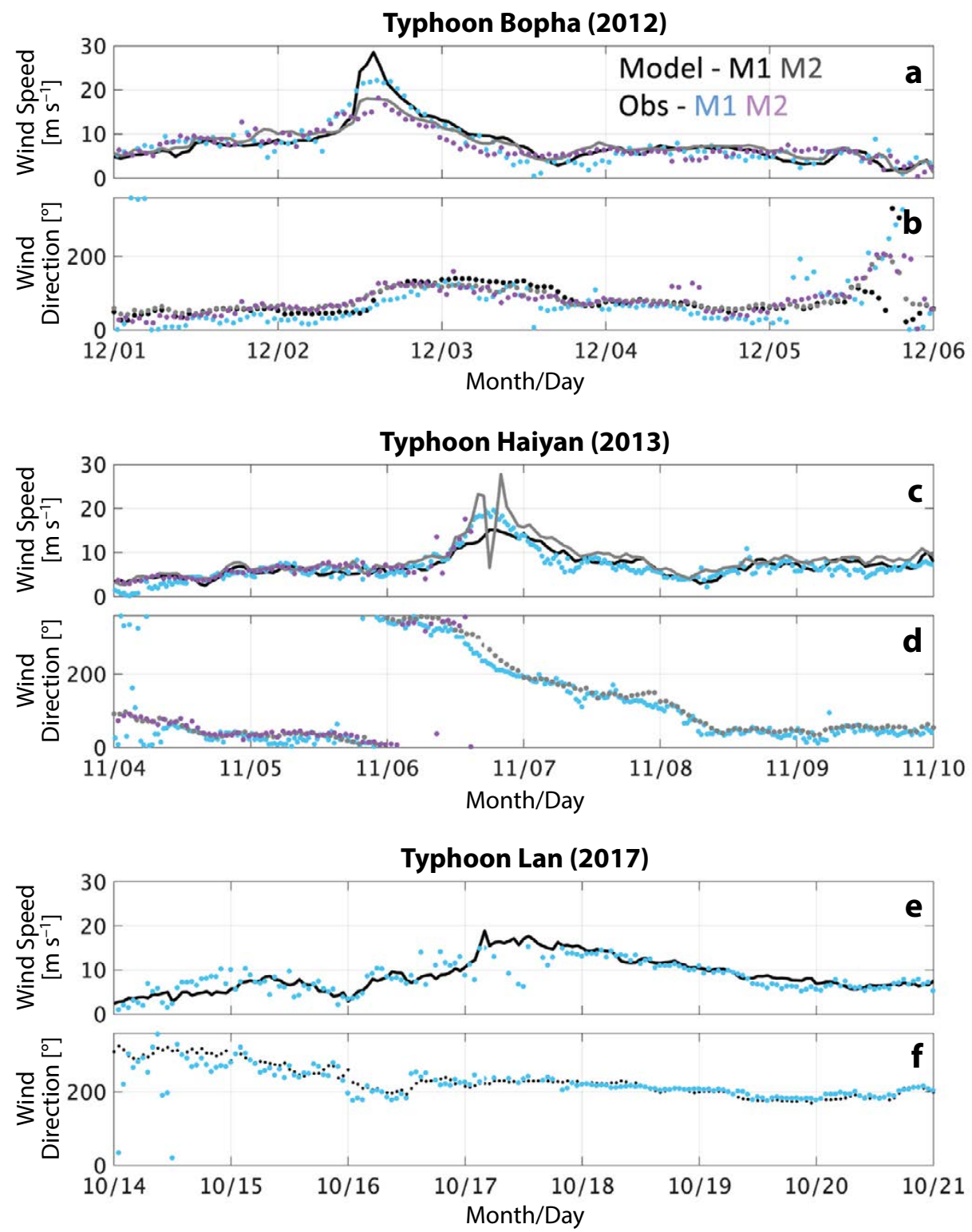

FIGURE 2. Measurements (blue, purple) and ECMWF model forcing (black, gray) of wind speed and direction for typhoons Bopha (a,b), Haiyan (c,d), and Lan (e,f). The model winds are shown at the closest point to the XMET stations, M1 and M2.

model was run on a $1 / 24^{\circ} \times 1 / 24^{\circ}$ spatial grid with spectral resolution of 48 directions and 32 frequencies using the source term package ST4 (Ardhuin et al., 2010). The atmospheric forcing was provided by hourly ECMWF reanalysis winds, which have $1 / 8^{\circ}$ nominal spatial resolution. All three runs used ETOPO2 (NCEI, 2006) bathymetry, whose resolution is approximately $3.5 \mathrm{~km}$ at the equator. Additionally, global, spatial advection, spectral advection, and source term time steps were set to $300 \mathrm{~s}, 100 \mathrm{~s}, 50 \mathrm{~s}$, and $5 \mathrm{~s}$, respectively. Boundary conditions were obtained from a global $1 / 2^{\circ} \times 1 / 2^{\circ}$ run with the same spectral resolution, model physics, and atmospheric forcing. The regional model was not run at a resolution to account for reef processes, wave transformation over the complex bathymetry, or surf zone physics.

\section{RESULTS}

The track of Bopha went $40 \mathrm{~km}$ south of Angaur, with winds and waves in its northeast quadrant impacting the entire eastern side of the main island group. Haiyan tracked directly over Kayangel with its northeast quadrant impacting Kayangel and the sunken atoll of Velasco Reef (Ngerunagel). Lan was unique in that the storm passed north of Palau, then stalled to the northeast without making landfall, and its subsequent forcing was more persistent, lasting on the order of a week. Measurements from XMET stations in the southwest (M1) and north (M2) captured wind speed and direction and barometric pressure as all three storms passed over the island group. During Bopha, XMET wind measurements peaked at $22.14 \mathrm{~m} \mathrm{~s}^{-1}$ on December 2, 2012, veering from northwest to southwest (Figure 2a,b). XMET wind speeds during Haiyan peaked at $19.56 \mathrm{~m} \mathrm{~s}^{-1}$ on November 6, 2013, and veered through $360^{\circ}$ prior to November 9, 2013 (Figure 2c,d). During Lan, maximum observed winds of $15.31 \mathrm{~m} \mathrm{~s}^{-1}$ occurred on October 17, 2017, and wind forcing was consistently from the southwest and northwest (Figure 2e,f). As a validation 
metric, model winds are compared to in situ winds measured at the two XMET stations (M1 and M2) during all three storms. There is strong agreement in both speed and direction between the observations and the modeled winds; root-meansquared differences between the speeds were less than $2 \mathrm{~m} \mathrm{~s}^{-1}$ for all storms, and vector correlation coefficients exceeded 0.87 for all sensors/model comparisons. Validation of the wind forcing used in the wave model provides confidence in the hindcast reanalysis.

Wave measurements collected during Haiyan and Lan showed strong gradients in significant wave heights around the island group. Time series of $H s$ during Haiyan are shown for gauges on the west side (W1, W3 in red, Figure 3a) and on the east side (E1, E3 in blue, Figure 3b). The maximum observed value of $\mathrm{Hs}$ was at gauge W3 (17.6 m depth), which recorded values close to $5 \mathrm{~m}$. Relative to the west side, measured values of $H s$ at gauges E1 (9.6 m depth) and E3 (13.8 $\mathrm{m}$ depth) were generally less than $2 \mathrm{~m}$ and up to $4 \mathrm{~m}$ lower than measurements at W1 (12 m depth) and W3. With the exception of W3 (Figure 3c), which was likely sheltered from the incident swell, spectrograms of energy density at each gauge (Figure 3d-f) show elevated energy at swell frequencies $(\sim 0.05 \mathrm{~Hz})$ preceding the higher frequency response that occurred two to three hours later.

During Lan, there were two notable wave events, with the first occurring between October 17 and October 19 and the second between October 23 and October 25, 2017. The first wave event was generated as the storm propagated from east to west, and the second event arrived after the typhoon strengthened, turned to the north, and radiated waves southward toward Palau. The significant wave height ranged from $<1 \mathrm{~m}(\mathrm{E} 4,13.7 \mathrm{~m}$ depth) to almost $6 \mathrm{~m}$ (W1, $11.8 \mathrm{~m}$ depth) during event 1 (Figure 4a,b). Similarly, $H s$ values ranged from about $4 \mathrm{~m}$ (W2, $12.6 \mathrm{~m}$ depth) to $<0.5 \mathrm{~m}$ (E2, $16 \mathrm{~m}$ depth and E3, $14.5 \mathrm{~m}$ depth) during event 2. In general, total significant wave heights measured on the west side of Palau were larger than those on the east side, with the exception of gauge E5 (15.4 $\mathrm{m}$ depth). The similarity of the frequency dependence of the wave conditions at E5, deployed on the north side of Kayangel, to that at the western gauges is attributed to its exposure to incident energy from the north and west. The spectral content at all gauges (Figure 4c-i) is characterized by peak energy near $0.1 \mathrm{~Hz}$ (10 s period) during event 1 , with broadband elevated energy across all frequencies (0.004-0.25 Hz). Gauge E4 is the exception, with less wave energy throughout, suggesting the sensor location is sheltered by surrounding local topography. Spatial variability in the spectral wave content during event 2 was much more pronounced. The wave climate was dominated by swell with a dominant period of 13 seconds on the western and northern sides of the island. The swell energy was strongest at gauges W2

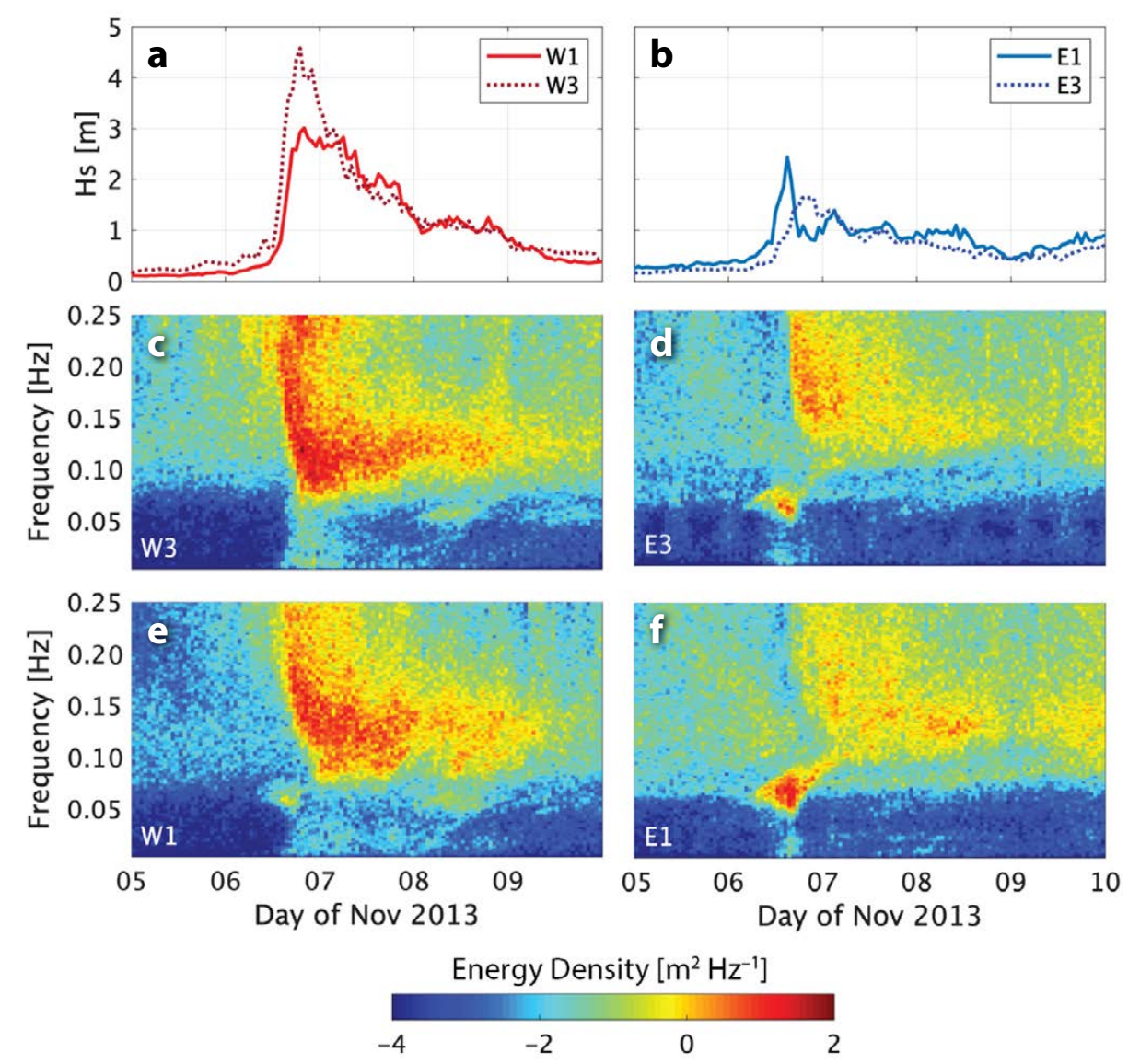

FIGURE 3. Measurements of significant wave height from the wave gauges are compared on the (a) west (red) and (b) east (blue) sides of the island during Typhoon Haiyan. Spectrograms of energy density (colors) are shown for stations (c) W3, (d) E3, (e) W1, and (f) E1.

and W5, while eastern gauges E2, E3, and E4 showed no elevated swell energy during event 2 .

To further study the spectral content of the wave field during the typhoon, significant wave heights are partitioned into two bands, seas (5-10 s period) and swell (10-20 s period). Directional spectra from WW3 model runs are azimuthally integrated to compute a onedimensional spectrum $\left(E_{f}\right)$. The resulting one-dimensional spectrum is partitioned using a cutoff frequency, $f_{p}$, of $0.1 \mathrm{~Hz}$ (10 s period) such that the significant wave height in the sea and swell bands, respectively, are computed as:

$$
\begin{gathered}
H s_{\text {swell }}=4\left(\int_{.05 \mathrm{~Hz}}^{f_{p}} E_{f} d f\right)^{1 / 2}, \text { and } \\
H s_{\text {sea }}=4\left(\int_{f_{p}}^{\infty} E_{f} d f\right)^{1 / 2} .
\end{gathered}
$$

At each grid point, the maximum values of $H s_{\text {sea }}$ and $H s_{\text {swell }}$ during the storms are shown in Figure 5. The band of the high-

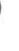



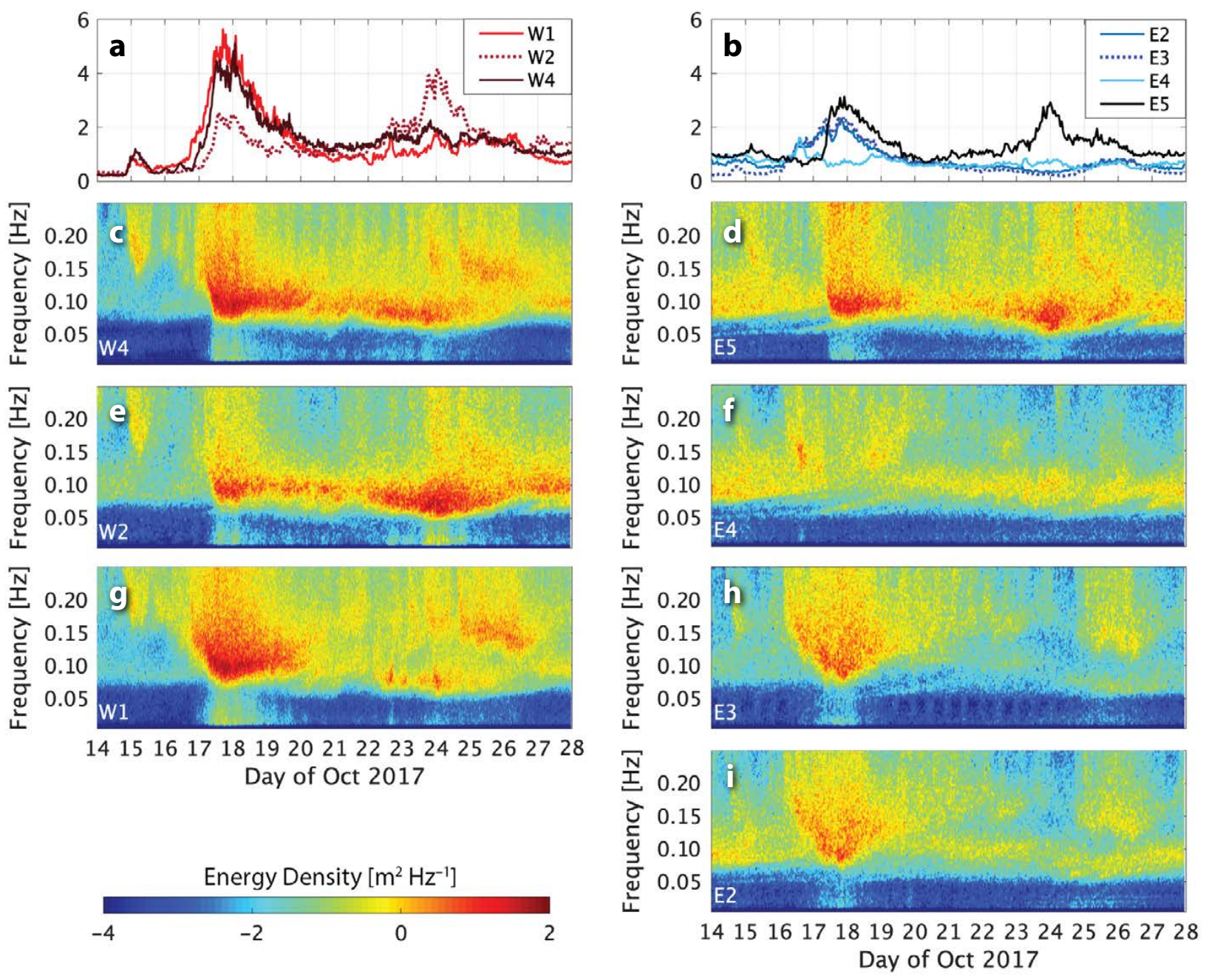

FIGURE 4. Same as Figure 3 but for significant wave height on the west (a) and east (b) coasts of Palau and gauges (d) W4, (d) E5, (e) W2, (f) E4, (g) W1, (h) E3, and (i) E2 active during Typhoon Lan in 2017.

est $H s_{\text {sea }}$ and $H s_{\text {swell }}$ values closely align with the storm tracks shown in Figure 1a. Values of $H s_{\text {sea }}$ exceeding $4 \mathrm{~m}$ extended to widths of $\sim 150-200 \mathrm{~km}$ along the storm track during both Bopha and Haiyan (Figure 5a,c), consistent with the $\sim 200 \mathrm{~km}$ radius of tropical storm strength winds for both storms (https://www.nasa.gov/ mission_pages/hurricanes/main/index. html). Hs $s_{\text {swell }}$ values show evidence of shadowing on the lee side of the island chain. During Bopha, swell energy is shadowed out to $\sim 125 \mathrm{~km}$ downstream of the island group (Figure $5 b$ ). The region between Angaur and Babeldaob faced the largest significant wave heights, with contributions from both sea and swell, consistent with visual observations of the primary reef damage. The reef was battered from the surface to $40 \mathrm{~m}$ depth.
$H s_{\text {swell }}$ during Haiyan was reduced on the west (lee) side of Palau, but the swell shadow is oblique and oriented southwest (Figure $5 \mathrm{~d}$ ). The orientation of the swell shadow in the model suggests that wave heights at both the eastern and western gauges, which were in the southern region of the island, may have been reduced relative to regions in the north where no direct observations were collected. Evidence of saltwater inundation of freshwater swamps located in the center of Kayangel Island and widescale damage to trees and structures were documented; however, areas of the west side seagrass bed were unscathed (Colin, 2018), suggesting that being sheltered in the lee of Kayangel Island was important in the protection of these areas.

In addition to sea and swell waves, infragravity (IG, 2-250 s period) energy is important in the nearshore environment, particularly as waves reach shallow water bathymetric features such as coral reefs. We estimate the IG energy by computing the significant wave height between 25 -second and 250-second periods at the gauges:

$$
H s_{I G}=4 *\left(\int_{.004 \mathrm{~Hz}}^{04 \mathrm{~Hz}} E_{f} d f\right)^{1 / 2} .
$$

Although total significant wave heights were comparable between Haiyan and Lan at the gauges, IG energy is much larger on the western side of Palau during Lan. All gauge measurements of $H s_{I G}$ during Haiyan and all eastern gauge measurements during Lan were less than $0.2 \mathrm{~m}$ (Figure 6). Larger values of $H s_{I G}$ corresponded to high values of total $\mathrm{Hs}$ on the west side of the island. 
Variations in $H s_{I G}$ between event 1 (large values at W1 and W4) and event 2 (large values at W2) are linked to the relative angle between the incident swell direction and the coastline orientation. We estimate a local coast-normal angle at gauges $\mathrm{W} 1, \mathrm{~W} 2$, and $\mathrm{W} 4$ of $250^{\circ}, 340^{\circ}$, and $285^{\circ}$, respectively. The relative angle, $\Delta \theta$, between the incident swell direction, estimated from the model, and the direction normal to the coastline is shown in the lower panel of Figure 6 . Higher values of $H s_{I G}$ correspond to relative angles closer to zero, consistent with the fact that swell that arrives from shore-normal incident angles leads to the strongest IG response (e.g., Herbers et al., 1995). Coral reef damage documented during Lan was most severe on the western side of the island, which is consistent with the incident wave energy and directions measured at the gauges and modeled by WW3. Lacking barrier and fringing reef, the west coast of Angaur was Palau's most heavily battered shoreline during Lan. Reef damage in this area extended as deep as $90 \mathrm{~m}$. This shore of Angaur has the same reef face direction $\left(250^{\circ}\right)$ as sensor W1, which recorded the highest $H s_{I G}$ during the initial passage of Lan.

\section{CONCLUSION}

This study presents in situ measurements and model output of the nearshore wind and wave climate during three major typhoons that passed near or over parts of the island nation of Palau between 2012 and 2017. All three westwardpropagating typhoons significantly damaged Palau, and subsequently the coastlines of the Philippines and Japan. Values of total significant wave height exceeded $5 \mathrm{~m}$ at certain gauges during both Haiyan and Lan, while other regions of the coastline had much weaker wave climates. Measured and modeled wave spectra show evidence of swell shadowing out to $200 \mathrm{~km}$ downstream of the island group and elevated infragravity energy when the incident swell direction is shorenormal to the coastline geometry. Coral reef inundation Gouezo et al., 2015) and
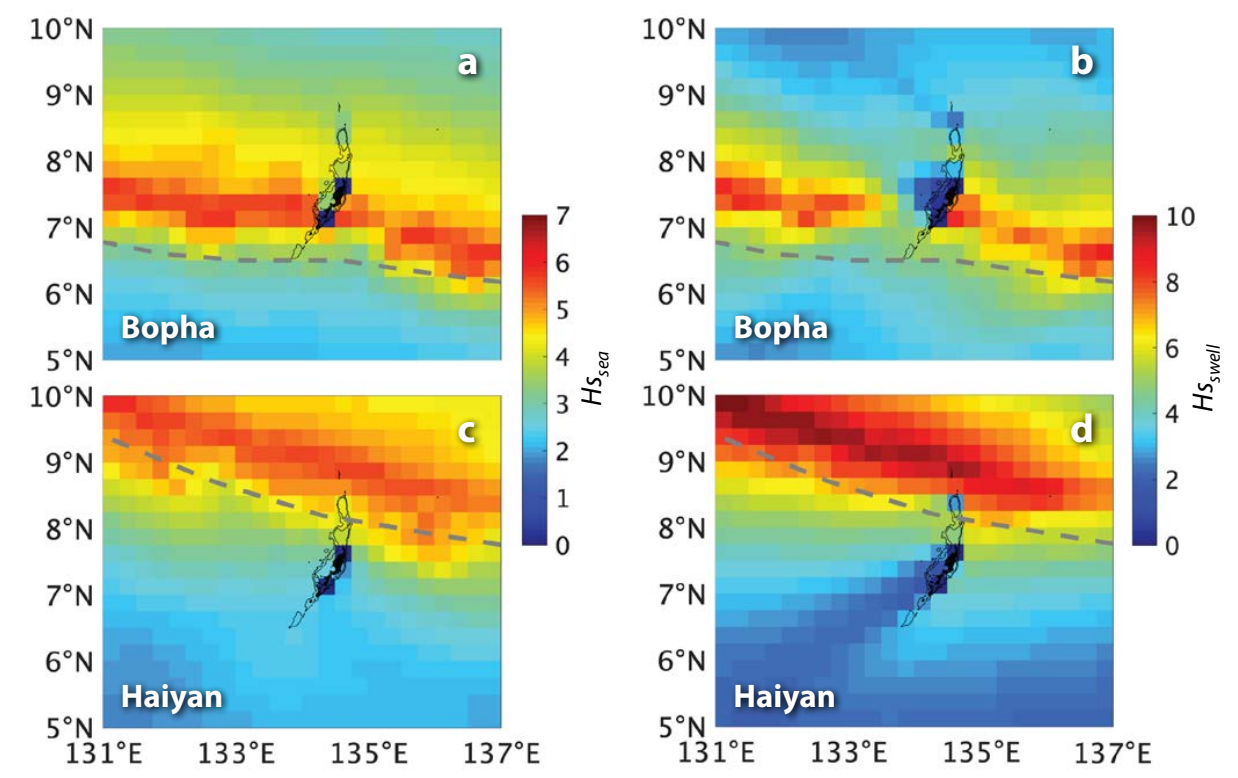

FIGURE 5. Maps of the maximum partitioned significant wave height during Bopha: (a) $H s_{\text {sed }}$ and (b) $H s_{\text {swell }}$, and Haiyan: (c) $H s_{\text {sea }}$ and (d) $H s_{\text {swell }}$ Gray dotted lines represent the observed storm track.
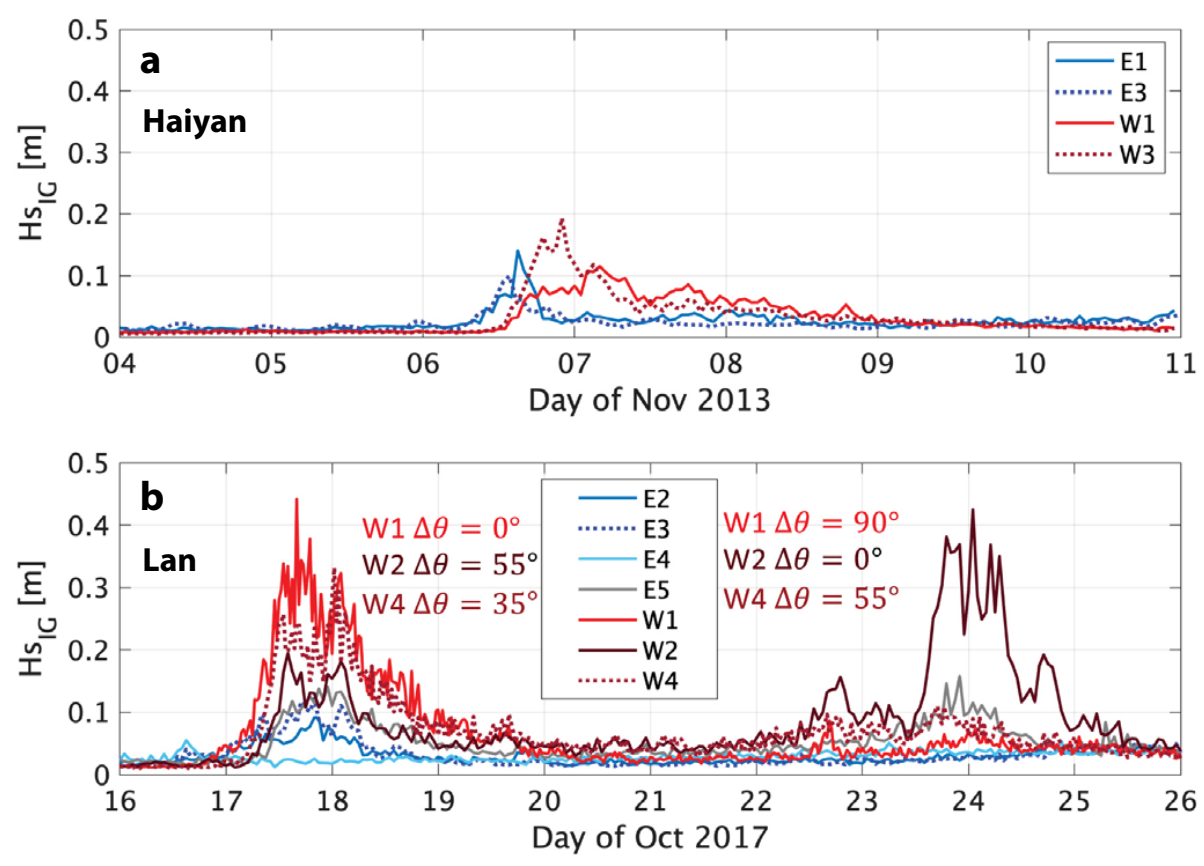

FIGURE 6. Estimates of significant wave heights in the infragravity (IG) band (25-250 s period) during (a) Haiyan and (b) Lan from the wave gauges. The relative angle, $\Delta \theta$, computed from the modeled incident swell and coastline orientation are shown for the western gauges during Lan when the largest IG energy was observed. 


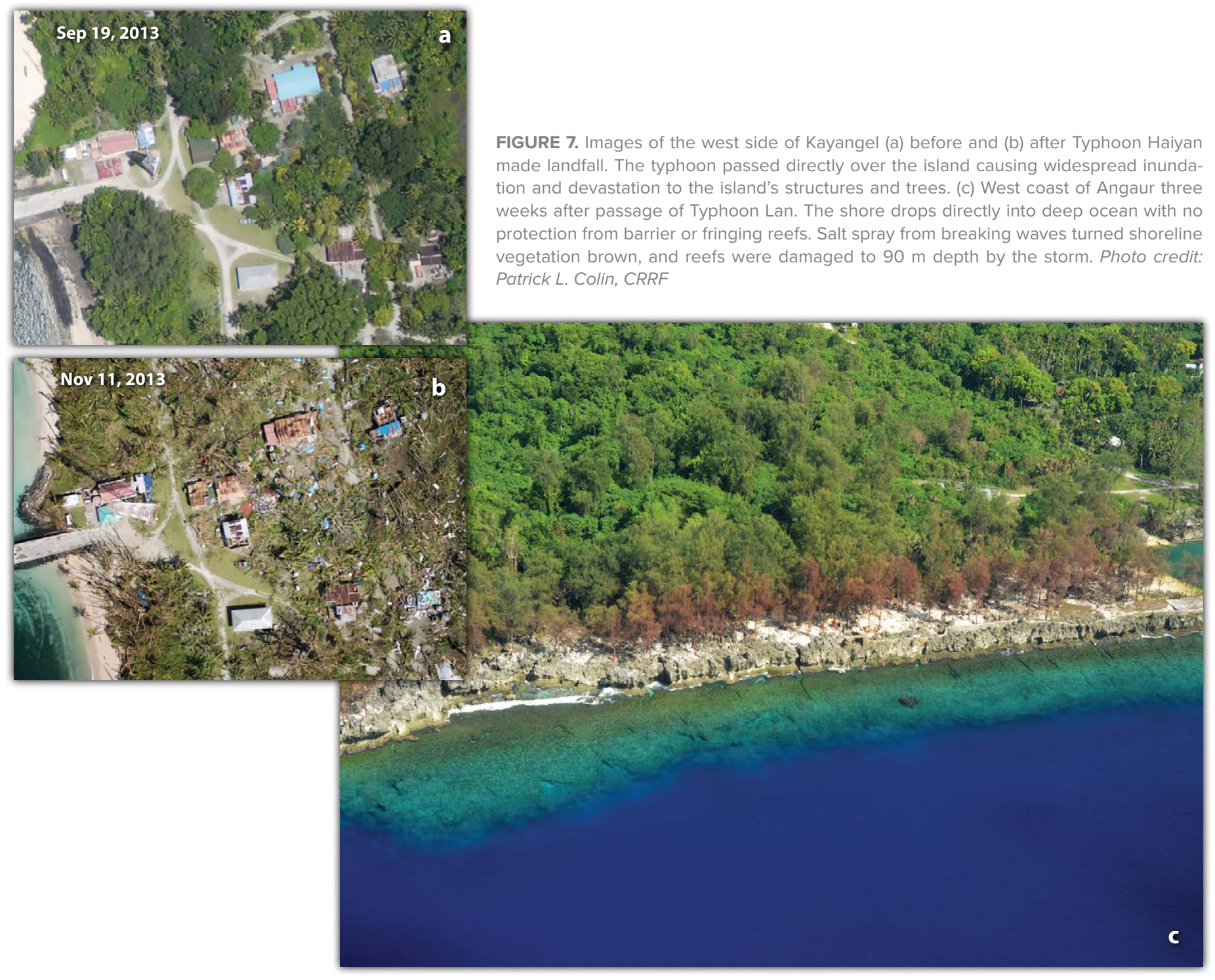

tree and structure damage along certain faces of the coastline were consistent with the directional wave climate during each storm (Figure 7) and the storm quadrant biases that resulted in highest shoreline impacts in regions to the right of the storm propagation. Images of typhoondriven destruction to the island nation of Palau (Bopha in title page image, Haiyan in Figure 7a,b, and Lan in Figure 7c) illustrate the range of impacts to Palau's diverse coastline and the need for persistent measurements to capture the complexity associated with extreme events.

The severe gradients of Palau's bathymetry and reef structure were not captured by the wave model resolution used in this study. Accurate representa- tions of nearshore wave setup and runup require topographic slope information and are the subject of future study. Higher resolution model runs, coupled with high resolution digital elevation maps, such as those now available through light detection and ranging (lidar) surveys, will help identify vulnerable areas of the coastline and the reef ecosystem where wave transformation will lead to damage and flooding. @e

\section{REFERENCES}

Ardhuin, F., E. Rogers, A.V. Babanin, J.F. Filipot, R. Magne, A. Roland, A. van der Westhuysen, P. Queffeulou, J.-M. Lefevre, L. Aoui, and F. Collard. 2010. Semiempirical dissipation source functions for ocean waves: Part I. Definition, calibration, and validation. Journal of Physical Oceanography 40(9):1,917-1,941, https://doi.org/ 10.1175/2010JPO4324.1.
Becker, J.M., M.A. Merrifield, and H. Yoon. 2016. Infragravity waves on fringing reefs in the tropical Pacific: Dynamic setup. Journal of Geophysical Research 121(5):3,010-3,028, https://doi.org/ 10.1002/2015JC011516.

Bishop, C.T., and M.A. Donelan. 1987. Measuring waves with pressure transducers. Coastal Engineering 11(4):309-328, https://doi.org/ 10.1016/0378-3839(87)90031-7.

Black, P.G., E.A. D’Asaro, W.M. Drennan, J.R. French, P.P. Niler, T.B. Sanford, E.J. Terrill, E.W. Walsh, and J.A. Zhang. 2007. Air-sea exchange in hurricanes. Bulletin of the American Meteorological Society 88(3):357-374, https://doi.org/10.1175/ BAMS-88-3-357.

Colin, P.L. 2018. Thalassodendron ciliatum (Cymodoceaceae) in Palau: Occurrence, typhoon impacts and changes over time. Botanica Marina 61(6):537-546, https://doi.org/10.1515/ bot-2017-0079.

Colin, P.L., and S.J. Lindfield. 2019. Palau. Pp. 285-299 in Mesophotic Coral Ecosystems. Y. Loya, K.A. Puglise, and T.C.L. Bridge, eds, Springer International Publishing, https://doi.org/ 10.1007/978-3-319-92735-0_16. 
CRRF (Coral Reef Research Foundation). 2014

A Summary of Palau's Typhoon History 1945-2013.

Technical Report, 17 pp., https://coralreefpalau.org/ wp-content/uploads/2017/05/CRRF-Palau-TyphoonHistory-2014-1.pdf.

Gawehn, M., A. van Dongeren, A. van Rooijen, C.D. Storlazzi, O.M. Cheriton, and A. Reniers. 2016. Identification and classification of very low frequency waves on a coral reef flat. Journal of Geophysical Research 121(10):7,560-7,574, https://doi.org/10.1002/2016JC011834.

Gouezo, M., Y. Golbuu, R. van Woesik, L. Rehm, S. Koshiba, and C. Doropoulos. 2015. Impact of two sequential super typhoons on coral reef communities in Palau. Marine Ecology Progress Series 540:73-85, https://doi.org/10.3354/ meps11518.

Herbers, T.H.C., S. Elgar, and R.T. Guza. 1995. Generation and propagation of infragravity waves. Journal of Geophysical Research 100(C12):24,863-24,872, https://doi.org/10.1029/95JC02680.

Holthuijsen, L.H. 2010. Waves in Oceanic and Coastal Waters. Cambridge University Press, 404 pp., https://doi.org/10.1017/CBO9780511618536.

Holthuijsen, L.H., M.D. Powell, and J.D. Pietrzak. 2012. Wind and waves in extreme hurricanes. Journal of Geophysical Research 117(C9), https://doi.org/ 10.1029/2012JC007983.

King, A.D., D.J. Karoly, and G.J. van Oldenborgh. 2016 Climate change and EI Niño increase likelihood of Indonesian heat and drought. Bulletin of the American Meteorological Society 97(12):S113-S117, https://doi.org/10.1175/BAMS-D-16-0164.1.

Kubota, H., R. Shirooka, T. Ushiyama, T. Chuda, S. Iwasaki, and K. Takeuchi. 2005. Seasonal variations of precipitation properties associated with the monsoon over Palau in the western Pacific. Journal of Hydrometeorology 6(4):518-531, https://doi.org/ 10.1175/JHM432.1.

Longuet-Higgins, M.S. 1952. On the statistical distribution of the height of sea waves. Journal of Marine Research 11:245-266.

Monismith, S.G. 2007. Hydrodynamics of coral reefs. Annual Review of Fluid Mechanics 39:37-55, https://doi.org/10.1146/ annurev.fluid.38.050304.092125.

NCEI (National Centers for Environmental Information). 2006. 2-minute gridded global relief data (ETOPO2) v2. National Oceanic and Atmospheric Administration, https://www.ngdc. noaa.gov/mgg/global/etopo2.html

Péquignet, A.C.N., J.M. Becker, M.A. Merrifield, and J. Aucan. 2009. Forcing of resonant modes on a fringing reef during tropical storm Man-Yi. Geophysical Research Letters 36(3), https://doi.org/ 10.1029/2008GL036259.

Roeber, V., and J.D. Bricker. 2015. Destructive tsunami-like wave generated by surf beat over a coral reef during Typhoon Haiyan. Nature Communications 6:7854.

Schramek, T.A., P.L. Colin, M.A. Merrifield, and E.J. Terrill. 2018. Depth-dependent thermal stress around corals in the tropical Pacific Ocean. Geophysical Research Letters 45(18):9,739-9,747, https://doi.org/10.1029/2018GL078782.

Shimozono, T., Y. Tajima, A.B. Kennedy, H. Nobuoka, J. Sasaki, and S. Sato. 2015. Combined infragravity wave and sea-swell runup over fringing reefs by super typhoon Haiyan. Journal of Geophysical Research 120(6):4,463-4,486, https://doi.org/ 10.1002/2015JC010760.

WAVEWATCH III Development Group. 2016. User manual and system documentation of WAVEWATCH III version 5.16. Technical Note 329, NOAA/NWS/NCEP/MMAB, College Park, MD, $326 \mathrm{pp}$.

\section{ACKNOWLEDGMENTS}

Logistical and field support were provided by Lori Colin, Sharon Patris, Gerda Ucharm, Matt Mesubed, and Emilio Basilius of the of the Coral Reef Research Foundation (CRRF), and by Shannon Scott and Mike Jilka of the Coastal Observing Research and Development Center. The authors wish to acknowledge the people and government of Palau for welcoming marine science in their country, with special acknowledgment to the Bureau of Marine Resources and the states of Koror, Kayangel, and Angaur that provided research permits to conduct this study. SM, ET, TS, and SC were funded by the US Office of Naval Research under grant N00014-15-1-2304 as part of the Flow Encountering Abrupt Topography (FLEAT) Departmental Research Initiative. ABVB was funded by NASA Earth and Space Science Fellowship award number 80NSSC17K0326. This work was made possible by vision and support from Theresa Paluszkiewicz and Scott Harper.

\section{AUTHORS}

Sophia T. Merrifield (smerrifield@ucsd.edu) is Project Scientist, Travis A. Schramek is an oceanographer, Sean Celona is Systems Integration Engineer, and Ana Beatriz Villas Bôas is PhD Candidate, all at Scripps Institution of Oceanography, University of California San Diego, La Jolla, CA, USA. Patrick L. Colin is Director, Coral Reef Research Foundation, Koror, Palau. Eric J. Terrill is Director, Coastal Observing Research and Development Center, Scripps Institution of Oceanography, University of California San Diego, La Jolla, CA, USA.

\section{ARTICLE CITATION}

Merrifield, S.T., T.A. Schramek, S. Celona, A.B. Villas Bôas, P.L. Colin, and E.J. Terrill. 2019 Typhoon-forced waves around a western Pacific island nation. Oceanography 32(4):56-65, https://doi.org/10.5670/oceanog.2019.411.

\section{COPYRIGHT \& USAGE}

This is an open access article made available under the terms of the Creative Commons Attribution 4.0 International License (https://creativecommons.org/ licenses/by/4.0/), which permits use, sharing, adaptation, distribution, and reproduction in any medium or format as long as users cite the materials appropriately, provide a link to the Creative Commons license, and indicate the changes that were made to the original content. 